few rare cases, where, apparently from an oblique and high opening in the membranes, discharges, such as you so accurately describe, came on for months before delivery; and yet all went ultimately well for both mother and child. Four out of six, however, end in premature labour." I felt afraid that another discharge of blood might occur at a month's interval from the last attack, and therefore watched the patient carefully at this time. Just exactly the day month from the former hæmorrhage (six months of pregnancy), I found her pulse quick, and face flushed, buit with no uneasiness or idea that anything unusual was to happen. I ventured to predict that there would be either a return of the hæmorrhage or a miscarriage that night. In about an hour afterwards, labour came on, and she was delivered of a six months' fotus. The amniotic sac was felt, as usual, full and tense, requiring rupture, after which a large quantity of amniotic fluid escaped. During all this time, I kept my patient in bed. The fluid in this case could not have been amniotic, as, from its continuance and profuseness, labour must have come on sooner, while the presence of the sac entire at labour requiring to be ruptured proved it.

At the next pregnancy, at about the corresponding period of advance in gestation, the same fluid again came away in the middle of the night in a gush. Having found on the former occasion that no effect in warding off the miscarriage was produced by keeping the patient in bed, I allowed her to rise, but requested her to keep the sofa for a week. At the end of this period, the discharge recurred as before. She then rose and went about as usual, but there was no further return of the discharge, and she went safely to term. She is at present pregnant a third time, and a third time has the discharge come on at the same period of pregnancy as at first. This time, the patient would not even keep the sofa for a clay, and there has been no return of the discharge. This is more than four months ago. There had been no exertion or fatigue to account for the last discharge.

\section{RUPTURE OF THE HEART.}

\section{By W. WINN WESTCOTT, M.B.Lond., Martock.}

S. V., aged 65, married, a carpenter, and a man of good general health and strength, in the summer of 187 I was struck on the forehead by the accidental recoil of an iron bar. This inflicted a wound which injured the temporal artery, and was followed by very free hæmorrhage. Last December, when returning home intoxicated from a neighbouring village, he fell over a bridge and struck his forehead against a sunken stone, inflicting a wound almost identical in position with the former. This wound also caused free hæmorrhage, which was stopped with considerable difficulty. Although not an habitual drunkard, he had drunk freely for many years, and was much shaken in health by the latter accident.

On February 26th, he was at a pullic-house during the evening, in his usual health, and drank moderately, returning home sober. The next morning, he got up feeling unwell, and walked to my surgery, about two hundred yards. As I was not up, he walked home again, and at 9 o'clock I went to see him. He was sitting by the fire, looking weak and ill; and presented very much the appearance of a man who had been iritoxicated overnight. He complained of pain at the epigas. trium and in the region of the stomach, of want of appetite, weakness, and chilliness. The bowels were constipated ; pulse weak, but regular tongue foul. I ordered two tablespoonfuls of the following mixture to be taken three times a day : Bo Spt. æetheris sulph. $3 \mathrm{ij}$; tinct. calumbre

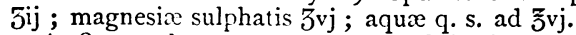

At 8 P.M., he appeared very much in the same state, but complained of nausea and severe pain over the stomach; yet he was lying quietly in bed, with features calm and pale. An hour later, he vomited much bilious matter and semi-digested food. The sickness then went off, and he took a basin of gruel. He expressed himself as feeling better, and his wife went to bed. In a short time, he roused his wife, asking her to make him some peppermint-tea. She did so, and he drank the tea. His wife then returned to bed, between 2 and 3 A.M. Some time later, he sat up in bed, put out the lamp which had been left burning by the bedside, and lay down again. Within ten minutes, he sat up, complained of feeling faint, and again lay down. His wife heard a slight rattling in his throat, upon which she got out of bed, struck a light, and found him dead.

Post Mortim Ixamination, thirty-one hours after death. - The body was well nourished ; the flesh firm. There was a thick layer of fat. The expression of the face was very much altered. There were two linear depressed scars over the lower part of the sternum. The stomach was congested, especially at the cardiac end. The liver was healthy; the splcen and kidneys were congested. The sternum was care- fully raised, without injury to the pericardium, which projected and seemed full and tense. The lungs were pale and normal. The pericardium was opened longitudinally, and about half a pint of serum escaped, leaving a teacupful of soft dark clot. The surfaces of the pericardium were healthy. The heart was removed entire ; and a very considerable deposit of fat on the surface and in the grooves of the organ was noticed. On the wall of the left ventricle, near the anterior border, were three longitudinal fissures : the two upper and smaller ones ex. tended through the pericardium and fatty layer only; the lowest and most anterior extended through the entire thickness of the wall, and measured rather over a quarter of an inch in length, and admitted a goose-quill easily. Internally, all the cavities were healthy, except the left ventricle; and all the valves appeared normal. The left ventricle was opened through the septum of the ventricle, and was found to contain soft dark clots, interlaced with the chordæ tendineæ and columnæ carnex. The clots were gently washed away by water; there were then seen several of the musculi papillares, ruptured, and their free ends covered by slight clots; and, near the anterior border, a long ragged zigzag fissure, three-quarters of an inch in length, corresponding to the principal external rupture ; its edges were also covered by small clots, but there was no continuous clot in the course of the wound. Several portions of the muscular substance were examined by the microscope, and were found to have undergone fatty degeneration.

\section{ILLUSTRATIONS OF SURGICAL DIAGNOSIS.}

\section{BY JOHN GRANTHAM, F.R.C.S., Crayford, Kent.}

Ar the district meeting of the South-Eastern Branch at Dartford, on April 24th, 1863, I read a paper on the necessity of comparative ob. servation in the investigation of injuries. The paper was published in the BRITISH MEDICAL JOURNAL for June 20 th of that year. The following case further supports my argument.

On August $\eta$ th, I87r, I was sent for to see Mr. E. W., who was suffering from an attack of colic. On the following day, he called my. attention to his inability to walk on the left leg without great pain, attended with impeded movement of the ankle-joint. This had been ascribed to some disease of the veins, but the patient considered it to be the effect of rapid mounting and dismounting. The narrative he gave of himself was: "On the morning of the Ist May, I867, at about two. o'clock, I was awoke with a sharp pain in my left groin. I struck a light and attempted to get out of bed (being at this time in the army at Athlone, Ireland), but found I could not stand, and that my left leg was immensely swollen. At eight o'clock I was assisted into the hospital, when I was treated for rheumatism, and had my leg bandaged with wadding and flannel. I was kept to my bed, when about a fortnight elapsed, and the pain did not decrease. Six leeches were applied to my groin, and the bandage was left off. After this, blisters were applied; my leg at this time being kept bandaged. After the blistering, iodine was used to paint my groin with. I was still kep? confined to my bed, with my leg elevated and bandaged. This treatment continued till the latter end of July, when my leg was rubbed with a lotion, and continued till the 16 th of August. All this time numerous doctors visited me, and could not give a name to my com. plaint. In September, I was allowed to walk a little, and continued till February, when I was put forward for discharge as incurable in ward. I may state the pain left my groin about the middle of August, and my veins in the abdomen took to swelling, and they have kept swollen since that time. Two men of great eminence in London saw me, and said it was one of those hidden complaints which were beyond human control."

On examination, I found the leg odematous, the heel elevated, and the flexor tendon on the fore part of the ankle-joint tense. On comparing the form and size of the gastrocnemius muscle of the injured leg with the one not injured, I found the muscular portion diminished in size, with evident division of the lower part next to the origin of the tendo Achillis. The foot was inverted so as to represent the appearance of a case of talipes varus. I diagnosed it to be rupture of the muscular part of the gastrocnemius, with partial dislocation of the anklejoint forward, as the foot could not be flexed, the joint being fixed. Regarding the case as one of partial dislocation, I made forcible extension for a time, until I perceived an audible movement of the lower or tarsal extremity of the tibia. I then suddenly flexed the foot to an acute angle with the tibia, which enabled him to move the joint in every direction. I then ordered hot fomentations, with perfect rest, for three days; at the end of which time he could walk on an even surface without any pain. After the three days' rest, the split or depression could very clearly be defined. On February 26 th, he resumed his duties as a railway 
clerk, which occupation involves long standing. $\mathrm{He}$ is at this time free from all appearance of swelling, which originally extended from the upper third of the thigh to the foot, and is able to walk any reasonable distance without pain, and with complete freedom of action of the foot.

\section{NEW FORMS OF VACCINATORS.}

\section{Bv A. B. STEELE, L.K.Q.C.P., Member of the National} Vaccine Establishment, Liverpool.

THERE is much reason to doubt whether the practical efficiency of vaccination is promoted or impeded, by the numerous attempts to complicate by ingenious mechanical contrivances a really simple though important little operation. Those who desire to witness the highest degree of uniformity and typical excellence which has probably been attained in this country in the production of Jennerian vesicles, may gratify their wishes by visiting the station of Mr. Marson, in Lambeth, whose experience and success in vaccination are probably unequalled, certainly not exceeded, anywhere. They will find that these desirable results are obtained by the use of the old-fashioned bleeding lancet, that being the instrument ordinarily used by $\mathrm{Mr}$. Marson for the insertion of lymph. In attaching undue importance to the form of the instrument used, there is some fear lest the far more essential points, namely the selection of lymph, and attention to other minute details, well understood by every experienced vaccinator, should be overlooked.

The latest novelty, the new form of vaccinator by Dr. P. M. Braidwood, figured and described in the JouRNAL of the I8th May, is really the Danish knife, a most efficient little instrument, with the addition of a joint in one blade.

The only real difference between this so-called new vaccinator and the Danish knife, which has been for many years used by Mr. Ceely (by whose recommendation I was led to adopt this mode of vaccinating), consists in the jointed blade which can be drawn back for the purpose of cleaning it. This object has been attained by a simpler and, as I think, preferable contrivance, which I adopted a few years since, viz., by the construction of the Danish knife on the principle of the crossaction forceps, so that by simple pressure on the handles both blades are separated and can be readily cleaned. Although it did not appear to me sufficiently important to publish this as a new invention, I had the pleasure some two years since of showing it to Dr. Braidwood; and if I am not mistaken it was at the Liverpool station of the National Vaccine Establishment that he first witnessed the mode of vaccinating on the Danish plan, which I quite agree with him in considering very efficient and satisfactory in its results. The instrument which I use can be made by any surgical cutler; it is kept in stock by Wood, surgical instrument maker, Liverpool, and will probably be less costly, a manifest recommendation when efficiency is not sacrificed to economy.

\section{FORCIBLE FEEDING OF THE INSANE.}

\section{By H. SUTHERLAND, M.B., M.R.C.P., Blacklands House, Chelsea.}

IN the JOURNAL of March 3oth, there appears a paper on "Forcible Feeding of the Insane", in which the writer states that he believes Paley's apparatus will be found efficient for feeding even in the severest cases of refusal of food. In the most severe cases that have come under my notice, Paley's feeder was not of the slightest use, although, doubtless, a valuable instrument in the subacute forms of insanity where food is refused. At the West Riding Lunatic Asylum, where there were sometimes as many as four patients to be fed by artificial means three times a day, endeavours were always made first to induce them to take their food naturally, feeding themselves. If that failed, an attendant would try to feed them, as one would feed a child or sick person, with a spoon. Sometimes an attendant's wife would persuade a male patient to take his food; and vice versi, the physician would often succeed with a female patient when the nurse had failed. If the patient still resisted, Dr. Williams's method of feeding with the spoon was tried, and, if that again proved a failure, the cesophageal tube was usually resorted to.

In the milder cases of refusal of food, the spoon, or Paley's feeder, will often answer the purpose very well; but in the severest cases, what are we do? The severest cases that I have met with are those of acute mania, occurring in the course of general paralysis. It may require five men to get such a patient properly into position; but if Dr. Williams's method be adopted, three ought to be sufficient to hold him while he is fed. His method of holding the patient is as follows. One at- tendant kneels at the head of the bedstead, with a knee on each side of the patient's head, which should be slightly raised; care being taken to put a soft towel between the knees and the patient's ears, which otherwise might be injured. This attendant also holds the patient's head with his hand. A sheet is thrown across the patient's body, and drawn down tightly upon him, especially at the knees. Two attendants then kneel on the sheet, one on each side of the patient's knees, so that his legs are held tightly in their place without the least risk of injury. Fach of the attendants then grasps one of the patient's arms, which should be left outside the sheet. The patient is thus held firmly, and without danger, by the three attendants. If there be more attendants, they are only in one another's way, and interfere with the movements of the medical man. The physician then opens the patient's mouth with the ordinary screw-gag, which the attendant holding the head should look after and keep in position. The tube is then passed. It is first dipped into the basin of liquid food, which is of course ready at hand and properly warmed. The tube may require to be slightly bent, about two inches from the end in some cases. The physician then inserts the tube, and along with it his forefinger, with which he feels for the epiglottis, slides it over it, and pushes about eighteen inches of the tube down the œsophagus. If this length of tubing go down without any grating or stoppage of any kind, he may be sure he has not passed his tube into the larynx. The food is then injected by the stomach-pump. I should mention here that $I$ have never seen the liquid food pass down the sides of the tube. It is true the patient may vomit the food ; and, if this occur, he should be immediately made to sit up, and the tube should be at once removed. When the food has all been pumped in, the tube should be withdrawn, and the basin placed under the cinin of the patient, to prevent the liquid which remains in the tube from running over the bedclothes.

A far better apparatus than any mentioned above is a large tin-funnel, to the narrow end of which is attached an India-rubber-tube about I 8 inches long, the other end of which fits into the stomach-tube, which should be about two feet in length and five-eighths of an inch in diameter. When the tube is fairly passed, the basin of liquid food is simply emptied into the funnel and finds its way into the stomach by the force of gravity.

Now, the reason for adopting the above method, insteal of using Paley's feeder, in severe cases of acute mania, is this : that these patients will often holloa and shout all the time they are being fed, so that it is impossible to prevent food, introduced by Paley's feeder, from. entering the larynx, which of course may be followed by serious consequences.

With regard to the indications for using the spoon, Paley's feeder, or the nasal tube, instead of the stomach-pump, I think such methois are to be adopted in the milder cases requiring forcible feeding, or when it is wished to make the process as disagreeable as possible, as in the case of lazy patients who refuse food merely by force of habit. But in the severest cases, there is no method equal to the stomach-tube, both for making a certainty of the patient getting his proper amount of food, and for providing for his safety more effectually than by any other system of artificial fecding.

\section{OBSTETRIC MEMORANDA.}

\section{PREMATURE RUPTURE OF TIE MEMIRANES.}

WITHIN the last month or two the consequences of this accident have been discussed in the JOURNAL, and opinions upon the subject have been so various, and even conflicting, that I had some weeks ago nearly resolved to give the facts of a case which presented itself many years since in my practice. The case left a strong impression upon my mind ; and, as through a period of forty years I have not had a similar one, I now report it as completely supporting the experience and views of Dr. Thorburn, of Manchester, who reproduces the subject in the JOLRNAi of May I8th, and whose third case exactly resembles mine in respect of the duration of gestation after the escape of the liquor amnii, while it shows at the same time that a term of six weeks' gestation after the accident is not incompatible with the safety and health of the feetus.

In the middle of January, 1836 , I was called to a woman, aged 27 , in her second labour, she having, as she stated, passed her seventh month of gestation. A regular course of pains soon completed the first stage, when the membranes suddenly ruptured, disclosing that the vertex was presented naturally - a fact which I could easily make out by digital examination. The point of my finger was distinctly in contact with the sutures, thus leading one to the conclusion that true liquor amnii had been discharged. I waited through the day in the expectation of speedy delivery, but, like Dr. Thorbuin, I got tired of 